\title{
Determinants of resilience for people ageing in remote places: a case study in northern Australia
}

\author{
BY HEATHER GIBB*
}

\begin{abstract}
The purpose of this study was to investigate how people managed to stay resilient as they aged in remote places. In Western developed countries, "successful ageing" is associated with older people's right to age in their chosen place. To remain resilient, older people require support to supplement diminishing self-reliance associated with increasing frailty. Such support services do not extend to remote communities, making it difficult to age in place. This article reports on a case study of ageing in remote places, from the perspective of seniors within a small community in remote northern Australia. The study found how older people attempt through volunteer efforts, to supplement the gaps in aged support services. This collective effort to achieve ageing in place demonstrated greater integration with place and social resilience within the community. However, seniors' social resilience was seen as tenuous, given collective self-reliance is based on volunteer efforts of older people.
\end{abstract}

Keywords: ageing, rural and remote, resilience, ageing in place, aged care services. 
International Journal of Ageing and Later Life

\section{Introduction}

This article reports on a case study of ageing in remote places from the perspective of seniors within a small community situated in remote northern Australia. The aim of the study was to seek an understanding, using an interpretive grounded theory method, of how people were growing old and managing to remain in a place of their choosing, despite there being no formal services to support ageing in place.

In Western developed countries, the phenomenon of population ageing is generating discussion about what it means to age successfully. The concept "successful ageing" is increasingly becoming synonymous with independence and choice (meaning physical self-reliance) (Stones \& Gullifer 2016). Governments in Western countries have generally adopted neoliberal health and social policy that favour this discourse (Anderson \& Kvist 2015). A major driver of neoliberal policy is concern with the costs associated with an ageing population and the projected growing demand on aged care services. A way around this rising cost is to promote strategies of self-reliance amongst older people. Advances in health and medical sciences have helped shape perceptions of the ideal older age as preserved health and an active lifestyle, continuing further into older age (Stephens et al. 2015). However, this ideal then becomes internalised as cultural markers by which older adults define the success of their own ageing and their identity (Keating 2008a; Tuohy \& Stephens 2016).

"Healthy ageing" programmes create a normalised standard of success defined by the body defying deteriorating changes or postponing changes normally associated with the ageing experience. It ignores the role of genetics and social factors in contributing to health and activity status in later life. "Active ageing" normalises success through social participation and activity that leads to the preservation of autonomy and selfdetermination. These programmes form part of the politicised discourse that, it is argued (Jones \& Heley 2016; Stephens et al. 2015), has the effect of placing expectations squarely on older people to preserve their independence and manage indefinitely, the challenges encroaching on their health, thereby avoiding adding to society's ageing problem of increasing rates of social welfare dependency. 
However, there is a tension in this discourse. For people to successfully age - maintaining health and remaining active - they require not merely physical endurance that defies the vicissitudes of getting older but also the social and physical supports within their environment to supplement their growing limitations (Scharf \& Bartlam 2008). This includes the availability of resources that sustain older people's capacity to meet physical and psychological changes as they happen and to adapt in order to remain independent (Stones \& Gullifer 2016). This article examines the tensions within the successful ageing discourse, as it applies to the context of isolated rural or remote communities. In these contexts, neoliberal government policy on successful ageing harnesses expectations within theories about what constitutes successful ageing. However, it fails to advocate the kind of support required to maintain capacity for successful ageing (see Keating 2008b; Skinner \& Hanlon 2016a).

Our discussion sketches the landscape of remote ageing in extreme climate conditions in Australia, comparing results from a small case study in tropical northern Australia with findings from research in other "extreme climate" contexts in Canada and northern Europe. It looks at considerations of the impact of lack of systems of support on seniors' ability to age actively in remote environments. In these small communities, unique scenarios of seniors' volunteer capacity (Hanlon et al. 2014; Skinner et al. 2014) belie the fragility of community resilience, which fades as these people grow older and can no longer care for themselves or each other. The long-term waning of resilience in these communities means the final cost - both fiscal and social, for governments and society generally - is substantial when the independence of these communities of seniors gradually disintegrates.

\section{Ageing in Remote Australia}

Our research was conducted in the Northern Territory (a central region of northern Australia), which has a population of approximately 240,000 residents, a third of whom are Indigenous. About half of these people live in sparsely populated regions, with a population density approximately 0.2 persons per square kilometre (Taylor \& Payer 2017).

Since the mid-1990s, there has been a marked increase in the number of people aged 65 years and over in this region, from 4337 in 1991 to 16,815 
International Journal of Ageing and Later Life

in 2015 (ABS 2016). The population of residents aged 65 years and over is projected to grow from 13,000 in 2011 to 46,000 by 2041 . The very old population (those 85 years and over) is projected to grow from just under 2000 residents in 2011 to just under 14,000 residents in 2041 (Taylor \& Payer 2017).

Historically, the trade and prosperity of Australia's Northern Territory relied heavily on primary industries leading to population growth in inner geographical regions. In particular, the growth of mining and resource extraction industries led to a growth in service towns across this region of Australia. The towns were essentially purpose-built to suit the needs of the local mining industry. However, in recent decades, in response to shifting global commodity demands, the mining industry has undergone downsizing and workforce populations have fallen in remote towns. This has left both a glut of cheap housing and an ageing population (Skinner et al. 2014; Zeng et al. 2014), as younger people move out in search of work elsewhere. This leaves older people without younger family members to take care of them as they grow older and frailer. Population ageing is happening faster in these isolated rural communities than elsewhere (Keating 2008b; Skinner \& Hanlon 2016a), creating what has been referred to as the neglected contexts of ageing (Skinner \& Hanlon 2016b).

Hanlon et al. (2014) describe a scenario common across Canada, Australia and other developed, resource-dependent countries (see also Skinner \& Joseph 2011, for a similar account of ageing rural communities in New Zealand). These are resource frontier towns and hinterlands that are isolated from services provided in larger urban centres (hospitals and specialist medical care, supermarkets supplying relatively cheap food and essential items). A familiar scenario is the closure of mines or other resource industries in their region, along with the cessation of services (public transport, banking and post, community centres and public libraries). In addition, there is the exodus of the community's youth in response to local unemployment.

In Australia, communities are defined in terms of remoteness using the ARIA index (ABS 2011). The region under study is classified as remote due to its location at considerable distance from a populated locality or service centre. Moreover, during the wet season, it can be cut off from accessible road transport. 
Although there has been some interest in learning about the plight of people ageing in parts of rural (or regional) Australia (e.g. Fiest 2016; Rogers et al. 2015; Taylor \& Payer 2017; Winterton \& Warburton 2014, 2016), very little has been done to directly understand the experience of growing older in the remote (or very remote) north. There are several possible reasons for this, such as cost and accessibility considerations in conducting research in these areas. The vast northern regions have a tropical climate with long periods of intense heat and humidity and periods of monsoonal rains, which, at times, block transport routes. It may also reflect a lack of awareness of the rate of ageing in remote communities. Most communities classified as remote experience lack of public transport, as well as unreliable communication networks.

The Australian government's policy for delivery of reliable, quality health care to remote and very remote communities (including Indigenous Australians who make up a relatively high percentage of the population in very remote northern regions) is inadequate by its own admission (RHSC 2011; see also NRHA 2011). Most remote communities have access to a remote primary health clinic. However, aged care services in Australia are generally provided by private or not-for-profit agencies that are located in cities and have a system of funded care designed for service delivery within an urban context. As such, this service model is not yet able to service remote communities (Productivity Commission. Caring for older Australians 2011), where complexity of service requirement is magnified by unique characteristics of these communities: small populations and difficulty of access. Access is exacerbated by frequent extreme heat conditions or during floods. As a result, older people who can afford to do so move to urban centres, at great distances from their community, family and friends, either to access community aged support or to enter residential aged care (Gibb 2017; Lindeman et al. 2017). This article argues that in Australia, policies governing practical servicing of the needs of aged people in these areas, supporting them to age in place, are virtually non-existent. This is a likely scenario globally. Given that ageing in remote regions in extreme conditions presents a relatively new problem for them, few developed countries have addressed the challenge of supporting these seniors to age in place.

This research article is an attempt to make a contribution towards the development of suitable policy directions for supporting ageing-in-place, through generating understandings of what it is like to be ageing within 
International Journal of Ageing and Later Life

the remote northern Australian context. A case study of one remote community and the experiences of older people who choose to live there is included as a beginning step towards identifying unique features of the Australian context that will help refine understandings of the global ageing phenomenon. This case study is the first stage of a larger research work using a grounded theory design to understand the diversity of meanings behind the experience of growing old in remote places in Australia's northern regions. Our research inquiry revolved around the relationship between resilience, ageing and living in a remote place. Our particular research questions were as follows: (1) What are the determinants of resilience for older people in this remote community? and (2) What is the relationship between resilience, ageing and this particular remote place?

\section{The Reality of Ageing in a Remote Place}

Ageing in place has been defined as "the ability to live in one's own home and community safely, independently, and comfortably, regardless of age, income, or ability level" (CDC 2013).

There is overwhelming evidence that it is a preference of older people to remain in their own homes and age in place (e.g. Kendig et al. 2017; Stones \& Gullifer 2016). This is exemplified in the growing appreciation of the relationship between ageing, place and community and its impacts on well-being (Wiersma 2016).

Temporality and place intersect dramatically, shaping meanings of growing old. With passing time, the capacity to follow a preferred lifestyle changes, along with the changing body, changing social connections, changing psychological strength and shifting identities of the self. The place one chooses to age in - normally one's home or one's community - is, at one time, a family and social hub. It may then take on meanings of solitary familiarity and comfort, evoking memories that reconfirm meaning and purpose. With changing time, the same place may require effort, challenging the person to confront loss, limitation and life's transformation. How well people transition these changes depends upon their resilience and the supports available to help them adapt to change. Van Abbema et al. (2015) identify protective or adaptive behaviours in older people as requiring both internal personal resources and external support resources. 
In isolated rural and remote environments, it is not easy to access the appropriate resources to assist transitions. Resource needs change over time and are dependent on the particular environment. They relate to the unique characteristics of the person and the unique relationships that ageing rural people forge with place (Daly \& Grant 2008). It is this diversity in resource need and flexibility in its delivery that Keating et al. (2013) argue really determines what makes an age-friendly community.

\section{Ageing People and Ageing Places - The Importance of Volunteering}

Ageing in many rural communities is supported by an immense willingness of older people to participate as volunteers to supplement services that are not there (Gjertsen et al. 2016; Rozanova et al. 2008; Taylor \& Payer 2017). In many of these reported cases, the volunteer work of retirees has served to reinvigorate the community economically and socially. Increasingly, however, the era of austerity and cost-cutting measures by governments are pushing out welfare responsibilities to community, with policy moves in the UK, Canada and other developed countries to mobilise the volunteer sector in the social care of older people (Jones \& Heley 2016; Milbourne 2016; Skinner \& Joseph 2011).

For the volunteer movements in already service-depleted rural communities, it is to some extent "business as usual." However, the redefinition of the community's roles in providing social care within neoliberal health and social policy means volunteering becomes an obligation rather than choice for retirees (Jones \& Heley 2016). It has no consideration of the impact of choice and motive in an older person's participation in volunteering, nor does it allow for diversity of age, resilience and physical well-being as variables impacting on people's capacity to volunteer.

\section{Resilience and Well-Being in Older Age}

Resilience is defined as "flourishing despite adversity" (Stephens et al. 2015), whereas well-being is used here as meaning an enduring sense of happiness or efficacy (van Abbema et al. 2015). Resilience is a consequence of sustained well-being and relates to capacity to endure. Heralded as an ideal state to accomplish, this discourse can, however, serve 
International Journal of Ageing and Later Life

to normalise individual responsibility to maintain well-being and to be self-reliant, irrespective of the types of adversity they may face. In other words, theories of resilience that do not consider the impact of available support and opportunity on a person's capacity to thrive in older age, stigmatise people who fail to thrive due to lack of personal health and support resources.

A more considered view of resilience is a capability approach (Sen 1987, cited in Stephens et al. 2015), which considers resilience in relation to a person's own values and their particular understanding of what it means to age healthily. Resilience is defined therefore as the capability to achieve certain functions a person values within their particular personal circumstances and social environment (Stephens et al. 2015).

Another approach is to view resilient ageing as "resourceful ageing" (Reynolds 2015), which emphasises the importance of investing in people's capacity and the resources they are able to use to sustain them during hardships. This is a dynamic approach, which accords with a model of resilience in older age, based on adaptation to adversity through protective internal and external resources (van Abbema et al. 2015). It implies that people are able to continually learn, grow and strengthen their own resource base, providing they live within an environment that provides external support resources that nurture the development of inner resources. According to van Abbema et al. (2015), it is on this platform that older people are able to maintain physical and psychological functioning that facilitates a sense of thriving. This implies a strongly preventative and primary health direction for ageing services, rather than a more common medicalised approach (Stephens et al. 2015). This has been the approach taken by the WHO in launching the age-friendly communities' campaign - creating settings or supportive environments in which older people can flourish (Eales et al. 2008).

Finally, Welsh (2014) suggests developing understandings of community resilience. Gale and Bolzen (2013) have applied a similar conception in their research with Indigenous Australian youth. They chose to adopt social or community resilience as a more sensitive methodological concept than resilience as an individual quality. This constitutes a shift towards recognising the centrality of relations and cultural context as resources critical to a persons' ability to maintain well-being. 


\section{Resilience in a Remote Community of Older People - A Case Study}

Our use of a grounded theory approach acknowledges diversity as an important component of theorising human experience as a function of the impact of environment on experience. Methodologically, it requires that the sampling for information gathering takes place across all variations of remote place including different population cohorts, in order for researchers to refine theoretical understandings of a concept such as resilience, with inputs from all possible sources of that experience.

Researchers who study human ageing and ageing communities emphasise the diversity of experience as a function of one's relationship with the place in which one lives (e.g. Keating 2008a; Keating et al. 2013). Diversity is extensive across the resource frontiers of northern Australia. Former mining towns are populated by people of largely European descent, along with Indigenous people who have settled in towns away from traditional homelands. Each of these groups may have been settled in this community or on the lands surrounding the township for several generations, or they may have recently relocated there for social reasons or employment. Then, there are Indigenous families who live in their traditional homelands, in the most remote and least accessible regions of the north. People are ageing in each of these contexts, and each cohort contributes a unique understanding of ageing in remote places in Australia.

The case study reported here is an investigation of the meanings of ageing and determinants of resilience within the perspective of the first of these cohorts - Australians of largely European heritage. Data that represent the perspectives of older Indigenous people, either those who have settled in remote towns or those living within traditional homelands, are currently being gathered.

\section{Methods}

\section{Setting}

The study was conducted in a region classified as remote, south west of Darwin. Out of a population of 1105 residents (ABS 2011), 112 residents were 65 years or over in 2011, with another 108 aged between 60 and 65 years. Members of this community were approached through the local 
International Journal of Ageing and Later Life

branch of Council of the Ageing, Northern Territory (COTA, NT), and invited to participate in the research. A "snowballing" method was used to invite other older people to participate in further interviews. Initial meetings and follow-up discussions were held in the local bowls club room, in the town that will be referred to by the pseudonym "Acacia."

\section{Participants}

Fourteen senior members of the community in and around Acacia participated voluntarily in an interview of no more than an hour and a half in length. All participants, except one 61 years old, were between 65 and 80 years old. This younger participant took part together with her older husband for whom she acts as a carer. No participant identified as an Indigenous Australian, and no participant was living in the same region as their children or other close family members.

\section{Process}

All interviews were conducted, by choice, in their own or a friend's home. Six participants were interviewed individually. Eight volunteered as a couple, so they were interviewed as a couple. Ethics approval to carry out the research was obtained from the Charles Darwin University Human Research Ethics Committee. Interviews were recorded digitally, then transcribed verbatim by the lead researcher. Transcripts were sent back to participants for review. Some made significant changes to content, usually eliminating references to the lives of other people.

Once transcripts were reviewed and validated by participants, open coding was carried out using NVivo software for interpretive data analysis.

Interview quotations were organised into a hierarchy of thematic categories, which were then subject to a further level of interpretation via the use of axial codes (Charmaz 2014). This step in interpretive coding draws out relationships between categories and subcategories and specifies properties and dimensions of the relationship. The coding proceeds by asking questions such as "who, when, where, why, how and with what consequences?" (Charmaz 2014: 147). From this level of interpretive coding, one or more core categories are chosen, which "encapsulates and explains the grounded theory as a whole" (Birks \& Mills 2015: 12). 
Two follow-up focus groups were held over the following 6 months involving these participants, who also invited friends or spouses (three additional seniors), working over the themes and adding further focus and clarity to identifying major common concerns for the ongoing well-being of this community. Topics emerging as key concerns for further discussion were transport, personal care support (PCS) and respite care support.

Researchers and community members also met socially during these field visits and people informally shared perspectives on thoughts generated in the interview. These became the subject of social conversation akin to spontaneous "thought gathering." Community members also emailed additional thoughts that elaborated on their responses or on some thought that developed following our field visit.

\section{Analysis and Findings}

The theoretical axiom emerging from the analysis of the textual data is "Securing Self in Place." Securing self in place refers to the capacity to remain living in a place of one's choosing, for as long as one chooses or prefers to live there. Although in the past there has been a view of ageing dominated by medicalised meanings - deterioration and dependency - the more recent discourses of well-being in older age shift the focus from dependency to active, self-determination about how one lives through older age. Within this framework, the importance of place and feeling secure within a place are key considerations. The responses of our participants capture the dynamic interaction of three concepts: the ageing self, security and place. The interaction of ageing self and place, which has been described extensively elsewhere (Keating 2008b; Skinner \& Hanlan 2016a), is in our study, crucially mediated by the establishment of four theoretical "axes" relating to securing self, as shown in Figure 1.

\section{Axis 1: Right Place}

The first axis represents the "rightness" of the place chosen to live in. Hanlon et al. (2014) refer to this important connection as place integration (Cutchin 1997, cited in Hanlon et al. 2014): “The process by which individual sense of self becomes intricately bound to place and manifested in a commitment to overcoming the challenges of everyday life." 
International Journal of Ageing and Later Life

Figure 1. Four theoretical axes that constitute the meaning of Securing Self Securing Self in Place

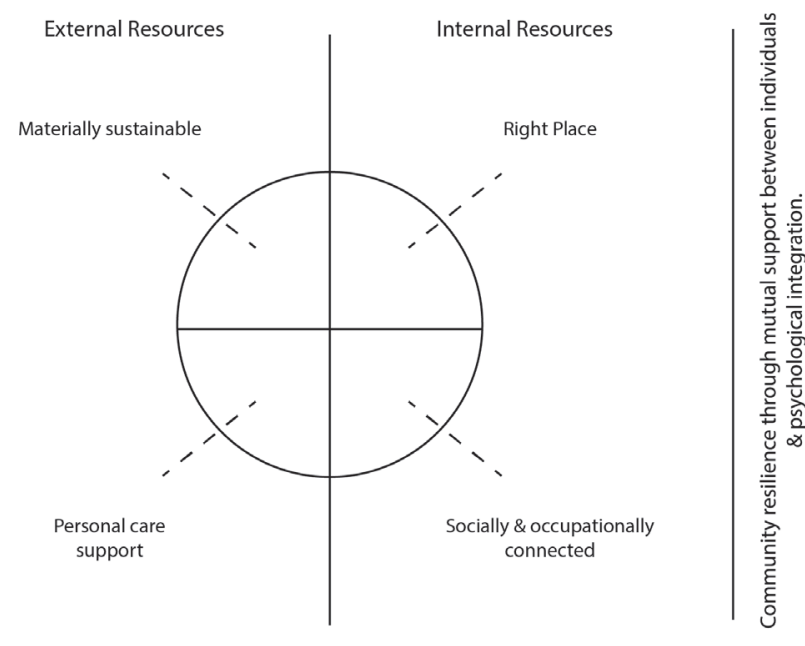

Resources to withstand the hardships of ageing in remote places.

This connection is primarily established through the alignment of several factors (see three subcategories below) and carries a strong sense of positivity and contentment.

Three conceptual subcategories of meaning contribute to the sense of this being the right place (RP). Below are supporting verbatim quotations from participants identified by a number (e.g. P1) and gender ( $\mathrm{M}=$ male, $\mathrm{F}=$ female).

Emotionally RP was linked to the feeling that this is the RP: Lovely little green place, lovely people, friendly people (P1, M); Yes you go a bit Bush happy here I suppose (P2, M). It was linked to practical material characteristics of the place that are attractive to retired people. It is a healthy environment: As you come past here, there is a bore, beautiful water (P1, M). It is a safe place: I have been able to go out and not lock my doors. There's virtually no crime here (P3, F). 
A sense of community was an important part of the feeling that this was the RP. Community contributed to the emotional connection with place: ...we made friends, we found the social energy of the community here was so great (P4, F); A community is close at hand: There's the Bowls club, Men's shed there; we've got our exercise classes. Everywhere you go, you meet someone you know to talk to. We've got a good library (P5, F).

Belonging to place meant that people had a sense of being anchored, enabling them to feel energetic and useful, but also accepted: It is my country and I didn't ever want to leave it... (P6, F); This is my adopted country; I made that decision sometime ago, that this would be my territory (P7, M). This place enabled one man to feel a sense of freedom to live more authentically: It is living, it is actually in a sense a contract you make within yourself, if you like. About where you belong and that you're going to live your life rather than prepare for some life in the future (P7, M).

\section{Axis 2: Socially and Occupationally Connected}

The second axis was the sense of being socially and occupationally connected through community (SOC). This involves a sense of purpose, which is essential for well-being to be maintained through older age (Lewis 2014; Ryff 2014).

Several people spoke about the intensity of the social connectedness in the community, both long-stay families and new in-migrant retirees: And then we started to get involved with community. And the community actually got involved with us (P4, F); you know if you join some organisation and you've been there two weeks and the AGM turns up, and oh, you've been here forever. So you can be the president, yes (recent in-migrants) (P8, M). For these new community members, initiation was often prompted through story telling: And we got all these lovely stories and I would just sit there mesmerised, you know, listening to the history of the place (P9, F). However, belonging together was most poignantly regarded as sharing the same hardships: We are all battling the same lack of facilities. And we are doing it in the only way we feel comfortable with (P3, F). The most common "battle" was named as trying to stay in this place as they confronted older age.

Hanlon et al. (2014) have argued how intense place attachment emerges through participation in community work in response to the problems brought up through living in that place. Here in this remote town, the 
International Journal of Ageing and Later Life

need for each person to be able to age in place is a collective galvanising point for volunteer activity. The community connection arising out of shared "battling" may well be a contributing factor to the intense positive feelings these people have towards the place.

\section{Volunteering}

Older people who valued this connection gave unconditionally of their time and effort to maintain the fabric of this belonging: So, I actually offered them to fill in any gaps that they required, to allow them to stay as long as they feel comfortable (P1, M); She knew I was a nurse. She rang me [and said], can you come and give me a hand (P10, F). In doing so, they share the knowledge that their investment in volunteering to help others is a critical glue to this community maintaining itself: And now I want to help these people, I want to be the next generation and I want to encourage another generation beyond that, to keep doing this, to keep the energy up because it works. It actually strengthens the community, brings us together. And we have a mutual cause and it's not necessarily just survival. It's about quality of life in a remote area (P1, M).

Volunteering amongst members of this community of seniors was most likely to be informal - helping each other on an individual level, as needs became evident. Senior community members often contributed their former occupational skills: plumber, school teacher, nurse, construction worker and public servant with knowledge about government departments. The age span was remarkable, with one 83-year-old woman still running music classes in the local school. The value of volunteering efforts of community members is in the way people work together, in a serendipitous way for the sake of community life: And people just work together. They ring up and say I need someone to help me do this and there is a little bit of negotiation and it's fixed (P9, F).

Some formally organised volunteering work existed, such as staffing the Tourist Information Centre in the town, as well as the establishment of an organised monthly community quiz night at the local bowls club and a weekly exercise class. Both of these community events were set up by in -migrant retirees. The two latter organised activities were established on principles of community capacity building - offering local people opportunity to develop skills in running the events, thus ensuring their sustainability. As the instigator of the quiz night event explained ...as my health 
Determinants of resilience for people ageing in remote places

deteriorated, I asked somebody who had been a regular, to co-quiz. And with that person's help, we've now got what we call pop-up quizzes, where anybody coming to quiz night can come with a round of 10 questions and do that at the night; it's along the lines of building the resource into the community and supporting people, to learn how to do questions etc. So they can be part of the quiz night (P8, M).

The exercise class has drawn so much enthusiasm and interest, and it has been "cloned" to a neighbouring remote town: To expand a little bit more on the energy that's there. I'll use the example of what I'm doing with exercise programs. There's a number of facets to this, but basically, it's about generating opportunities for people, particularly older people, to be involved in exercise. Last week was the first week of a new group in Casuarina (pseudonym for neighbouring town) (P7, M).

The shared desire for community members to stay active and healthy, thereby ageing in place, provides an impetus for developing capacity to establish and expand programmes. This would ensure that ownership is vested in the community, not individuals: ...that enables you to sustain a locally energetic activity. And the same is true with the exercise group. I've now got two people who are right into yoga, who, if I can't be at the session we have here on a Tuesday night, I know that I can ask them to do it. And I've said to the people in Casuarina, that's where I want to be with this group over a period of time. But here it's taken eight years. We're not looking at a flash in the pan, 12month program and stuff like that $(\mathrm{P} 7, \mathrm{M})$.

Several people described the added depth to friendships when people volunteer to work together for the sake of their community life. One example was a description given by a man who was a recent in-migrant, of his friendship through volunteering, with a long-stay resident as the latter was coming to terms with early signs of dementia:

He remembers very specifically he and I, and the therapy that we had with each other, just doing renovations in the museum buildings...You know he would put a tool down or you would ask him to go and get a tool and he would come back with something different. "B...Wow!" "Well, what did you ask me for?" And so we would go back through it again, but it was never a challenge. It was always a joke, it was always an issue, it was all therapy. I think he realised it was happening but it's like the rest of us, you know, we deny these things, and perhaps it's just the thought that maybe it's not really happening to us and maybe it would just go away and we'll all be ok (P1, M). 
International Journal of Ageing and Later Life

Volunteering for the community was deeply valued and embedded in the local culture over generations, as described by a recent in-migrant: This is their strength and their knowledge. They have built on that, to actually fill the gap of the facilities that weren't here. It is what their parents taught them, to fill the gaps that were required in this remote area $(\mathrm{P} 1, \mathrm{M})$.

Volunteering was like a bartering system that generated a sense of shared purpose. People felt obligated to pay back the help they were given, as a matter of self-respect: But most people underneath, they have an obligation to pay back the favour, if not to that person, to at least someone else. I think that's what makes the energy go round (P9, F). When these people were asked, why they invest effort later in life in helping others, the response has been that unconditional effort opens the community to you: ... acceptance, appreciation, respect, and you don't need more than that. And generosity; friendship and respect (P4, F). Moreover they saw generosity as an investment in building and sustaining mutual commitment - that willingness to do it (P11, M) - in a community that has to rely on itself.

\section{Axis 3: Material Sustainability}

The third axis, material sustainability (MS), carries the associated meanings of being able to provide for one's material needs adequately, including affordable housing and access to affordable food and clothing (this is not always achieved shopping locally). This theme of negotiating a way to sustain basic needs reflects the poverty threatening remote communities. This was a small category because people generally were not interested in dwelling on the need for frugality and going without. The fierce self-reliance ensured that material need was unlikely to be expressed: And I think people we've grown up with are not looking for the great material things. And to live in an area of community where all this stuff is not laid on...everyone is on an even par, and we're all battling the same, you feel equal, therefore you all hop in together. I'm happy with a simple life. And that's why -the small community gives you a simple life (P3, F).

MS referred to having the basics like affordable housing: A few old people ended up in [Acacia] because houses were relatively cheap compared with Darwin $(\mathrm{P} 2, \mathrm{M})$.

Similarly, it was about being able to access reasonably priced food: There's a general store in [Acacia] which provides necessities, but...people go ... to Darwin and buy their groceries rather than buy them from the [local] 
supermarket...if you're on a pension you can't afford to buy them from the [local] supermarket (P12, F).

The need to be able to buy cheaper products in the city meant that transport was a high priority for older people ageing in this community: The biggest thing I hear is people getting to town and back. We don't have a bus here. Even twice a week or something. If we had a bus, [that] ran from here to town $(\mathrm{P} 3, \mathrm{~F})$.

\section{Axis 4. Personal Care Support}

The fourth axis was PCS requirements, meaning to have assistance when needed to be able to manage one's personal physical needs. People's vulnerability - not being able to manage one's personal care needs alone - is a common scenario that potentially faces them all. It was the most likely scenario that would force them to leave. The following is a quote from a woman whose husband has early dementia: I used to always wonder why people lived here all their lives and went away down south in their retirement. And they used to say, there's no facilities up here for older people... [Our] intention was to stay here until our health was the thing that took us away and unfortunately, it's happened earlier than what we thought. And so we have to move... But it's very, very hard because my life is here (P6, F).

Everyone interviewed shared stories about people for whom help was not reliably available: We don't have the help and have to turn - when I was caring for my husband ...he couldn't be left alone, because he used to fall. And I got offered maybe two hours once a month if I was lucky, to go shopping (P3, F); I know a couple of elderly gentlemen who lived in the flats in [Acacia]. They waited and the help [in personal care] never came (P6, F).

$\mathrm{RP}$ and SOC contribute to forming a psycho-spiritual platform of security - which equates with internal resources, whereas MS and PCS together constitute a platform of practical sustainability - which equates with external resources. Our respondents' stories indicate that both kinds of security are needed to form an outlook of psychological well-being.

\section{General Discussion and Conclusion}

The significant relationship between ageing and place has received further validation in this study. Place constitutes a set of conditions for sustaining 
International Journal of Ageing and Later Life

resilience, particularly psychological integration and belonging. Place also held strong emotional connection for these participants; as well as its natural beauty, what seemed to be most important was their own personal choice in being there. The degree of commitment to this place is comparable with the notion of "integration with place," which Cutchin (1997, cited in Hanlon et al. 2014) describes as occurring through shared opportunity to participate in solving practical problems affecting life, in that place. This case study has highlighted the relationship between holding place and securing a sense of self. It depicts the use of active agency in securing self through identifying and locating resources related to the four axes.

Psychological resilience has been described as a hardiness in the face of loss or social threat. It has been described as a personal resource comprising traits of self-reliance as well as equanimity (Mlinac et al. 2011). Although both these traits were evident from our interviews, seniors' accounts also included a strong altruistic trait, expressed through an interest in the well-being of others and activity undertaken, both as individuals and collectively, to ensure the safety and comfort of each other. Research in other community contexts (e.g. Hildon et al. 2010) has shown that social support is correlated with resilience. More specifically, socio-emotional support (not instrumental support) has been shown to contribute to higher quality of life for older adults (Netuveli \& Blaine 2008). Another important trait that contributes to resilience in older age is a sense of worth and purpose (Clark et al. 2011). Our findings indicate that the opportunity to derive purpose from supporting others may contribute to resilience for older people in remote settings.

Resilience also relates to communities, in particular their capacity to collectively galvanise resources to withstand common stressors (Hochhalter et al. 2011; Vaneeckhaute et al. 2017).

Community or social resilience is often described using metaphors of resilience in physical systems derived from physical sciences such as engineering: Within a physical system, resilience connotes the capacity to accommodate, adapt or recover from stresses. Resilience refers to behaviours and activities that occur in response to the stress to withstand its impact and the consequences of those actions. The phenomenon of community resilience includes the strength of community capacity, which needs to be adequate to meet the force of the stresses - if not it reaches a 
point where community function will inevitably falter (Pfefferbaum et al. 2017). In our study of an ageing community, the absence of resources both to operate community facilities and to accommodate changing needs of individuals for support, indicates that a point will come where community capacity will not be able to accommodate the threats and challenges associated with collective ageing.

Collectively, the resilience of the community lies in being able to mutually negotiate the resources that van Abbema et al. (2015) have described as essential determinants of resilience. With these resources in place, capacity of the community would then be enhanced; people would stay and support the continued functioning of community enterprises. (The enduring industry in this town is tourism; these seniors operate both the information centre and the historical war museum - a significant tourist attraction.) In turn, servicing the needs of these people for ageing in place provides increased opportunity for local work and a service industry that would enhance "grey nomad" tourism in the region. This accords with Gale and Bolzen's (2013) conception of community resilience, where relations with other people and context or "place" are key determinants of resilience.

Just as in communities described in remote areas of northern Europe and Canada (Keating 2008b), this community is ageing, and its capacity to maintain what van Abbema et al. (2015) classify as external resources over time will diminish without added resources. In this study, all participants either owned their own home or had sufficient subsistence from the aged pension to pay rent and buy food. They also had access to free medical care for acute and chronic health conditions at their local remote health clinic. Moreover, our case study has indicated how exchange of mutual help assisted people locally to reach a basic level of MS. All this meant that the requirement of MS was adequately met (for a fuller discussion on the impact of low MS on the resilience of older people, see McMunn et al. 2006). PCS, however, was not and this was critical to these people being able to age in place. Unlike MS where people were reasonably self-sustaining, deficits in PCS constituted their greatest vulnerability, in this place. Without formal services of support, it was only a matter of time before people failed in their capacity to age in place. This vulnerability is discussed extensively elsewhere (e.g. Fiest 2016; Gibb 2016, 2017). 
International Journal of Ageing and Later Life

Resilience requires external supplementary resources; however, social resilience requires that these additional resources not take away the purposefulness, the "energy" of working for the community and providing mutual help that integrates person and place. Social resilience is a dynamic phenomenon. "Off-the-shelf" aged care packages are not the answer to the service needs of remote community members, as these threaten the subtle relationship older people have with other community members (mutual help) and with place (integration with place forged through attending mutual problems).

On its own, this study, limited as it is to one small community of seniors, is likely not to generate findings representative of other communities in remote northern Australia. Every community differs in its resources and its deficits in supporting ageing in place. However, the stories from these seniors provide a unique understanding of how resilience in one community is strengthened through mutual responses to the threat to securing one's life in a chosen place, with the advance of ageing and physical vulnerability. Service providers can apply this understanding at a general level in their approach to working with remote communities. When an inquiry is opened up about how to support community resilience in remote ageing communities, the appropriate response will always be about engaging with each unique community - not delivering an individual care package.

\section{Acknowledgements}

The author would like to thank senior community members in the research site for their energetic support of the project and their time in sharing their stories about ageing in a remote place. The author would also like to acknowledge the research assistance of Brian Eacott and his feedback on earlier drafts of the manuscript, and the assistance of Lai Yin Gibb-Cheng in the design of Figure 1.

\section{Corresponding Author}

Heather Gibb, College of Indigenous Futures, Arts and Society, Charles Darwin University, Darwin, Northern Territory 0909, Australia. Email: heather.gibb@cdu.edu.au 
Determinants of resilience for people ageing in remote places

\section{References}

Anderson, K. \& Kvist, E. (2015). The neoliberal turn and the marketization of care: The transformation of eldercare in Sweden. European Journal of Women's Studies 22(3): 274-287.

Australian Bureau of Statistics (ABS). (2011). ARIA Index. Available on www.abs.gov.au/austats/abs@nsf/mf/1270.0.55.005?OpenDocument (Accessed: May 15, 2016).

Australian Bureau of Statistics (ABS). (2016). 3101.0 - Australian Demographic Statistics. Available on http://www.abs.gov.au/AUSSTATS/abs@.nsf/ DetailsPage/3101.0Sep\%202015?OpenDocument (Accessed: July 1, 2017).

Birks, M. \& Mills, J. (2015) Grounded Theory: A Practical Guide (2nd ed.). Los Angeles, CA: Sage Companion.

Centers for Disease Control and Prevention (CDC). (2013). Healthy Places. CDC series 24/7: Saving lives, protecting people. Available on www. cdc.gov/healthyplaces/terminology.htm (Accessed: May 15, 2016).

Charmaz, K. (2014). Constructing Grounded theory (2nd ed.). London, UK: Sage.

Clark, P. G., Burbank, P. M., Greene, G., Owens, N. \& Riebe, D. (2011). What do we know about resilience in older adults? An exploration of some facts, factors, and facets. In B. Resnick, L. P. Gwyther \& K. A. Roberto (eds.), Resilience in Aging: Concepts, Research, and Outcomes (pp. 51-66). New York, NY: Springer.

Daly, T. \& Grant. G. (2008). Crossing borders: Lifecourse, rural ageing and disability. In N. Keating (ed.), Rural Ageing: A Good Place to Grow Old? (pp. 11-20). Bristol, UK: Policy Press.

Eales, J., Keefe, J. \& Keating, N. (2008). Age-friendly rural communities. In N. Keating (ed.), Rural Ageing: A Good Place to Grow Old? (pp. 109-120). Bristol, UK: Policy Press.

Fiest, H. (2016). Ageing in rural Australia. Australian Ageing Agenda August: 16 .

Gale, F. \& Bolzen, N. (2013). Social resilience: Challenging neo-colonial thinking and practices around 'risk'. Journal of Youth Studies 16(2): 257271. doi: $10.1080 / 13676261.2012 .704985$

Gibb, H. (2016). Five years on from the inquiry: Caring for older Australians, what is the viability of ageing in remote places, in Australia? Research Report, Northern Institute, Charles Darwin University. Available on www.cdu.edu.au/northern-institute/research 
International Journal of Ageing and Later Life

Gibb, H. (2017). Remote aged care: Bush communities need different approach. Community Care Review Winter: 10-11.

Gjertsen, T., Ryser, L. \& Halseth, G. (2016). Gamvik, 'a good place to grow old: The role of voluntary organizations in an ageing resourcesdependent municipality in northern Norway. In M. Skinner \& N. Hanlon (eds.), Ageing Resource Communities: New Frontiers of Rural Population Change, Community Development and Voluntarism (pp. 106-118). London: Routledge.

Hanlon, N., Skinner, M., Joseph, A., Ryser, L. \& Halseth, G. (2014). Place integration through efforts to support healthy aging in resource frontier communities: The role of voluntary sector leadership. Health and Place 29: 132-139. doi: 10.1016/j.healthplace.2014.07.003

Hildon, Z., Montgomery, S. M., Blane, D., Wiggins, R. D. \& Netuveli, G. (2010). Examining resilience in the face of health related and psychosocial adversity at older ages: What's right about the way we age? Gerontologist 50(1): 36-47.

Hochhalter, A. K., Smith, M. L. \& Ory, M. G. (2011). Successful aging and resilience: Applications for public health and health care. In B. Resnick, L.P. Gwyther \& K.A. Roberto (eds.), Resilience in Aging: Concepts, Research, and Outcomes (pp. 15-30). New York, NY: Springer.

Jones, L. \& Heley, J. (2016). Practices of participation and voluntarism among older people in rural Wales: Choice, obligation and constraints to active ageing. European Society for Rural Sociology, Sociologica Ruralis 56(2): 176-196. doi: 10.1111/soru.12073

Keating, N. (2008a). Revisiting rural ageing. In N. Keating (ed.), Rural Ageing: A Good Place to Grow Old? (pp. 121-130). Bristol, UK: Policy Press.

Keating, N. (ed.). (2008b). Rural Ageing: A Good Place to Grow Old? Bristol, UK: Policy Press.

Keating, N., Eales, J. \& Phillips, J. (2013). Age-friendly rural communities: Conceptualizing 'best-fit'. Canadian Journal on Aging 32(4): 319-332. doi: $10.1017 /$ S0714980813000408

Kendig, H., Honge Gong, C., Cannon, L. \& Browning, C. (2017). Preferences and predictors of ageing in place. Longitudinal evidence from Melbourne Australia. Journal of Housing for the Elderly 31(3): 1-13.

Lewis,J. (2014). Therole of the social engagement in the definition of successful ageing among Alaska native elders in Bristol Bay, Alaska. Psychology and Developing Societies 26(2): 263-290. doi: 10.1177/0971333614549143 
Lindeman, M. A., Smith, K., LoGiudici, D. C. \& Elliott, M. (2017). Community care for Indigenous older people: An update. Australasian Journal on Ageing 36(2): 124-127. doi: 10.1111/ajag.12316

McMunn, A. Breeze, E. Goodman, A. Nazroo, J. \& Oldfield, Z. (2006). Social determinants of health in older age. In M. Marmot \& R. G. Wilkinson (eds.), Social Determinants of Health, 2nd edition (pp. 267-296). Oxford, UK, OUP.

Milbourne, P. (2016). Austerity, welfare reform, and older people in rural places: Competing discourses of voluntarism and community? In $\mathrm{M}$ Skinner \& N. Hanlon (eds.), Ageing Resource Communities: New Frontiers of Rural Population Change, Community Development and Voluntarism (pp. 74-88). London: Routledge.

Mlinac, M. E., Sheeran, T. H., Blissner, B., Lees, F. \& Martins, D. (2011) Psychological resilience. In B. Resnick, L. P. Gwyther \& K. A. Roberto (eds.), Resilience in Aging: Concepts, Research, and Outcomes (pp. 67-88). New York, NY: Springer.

National Rural Health Alliance (NRHA). (2011). Improving the Prospects for Healthy Ageing and Aged Care in Rural and Remote Australia. Submission in response to the Productivity Commission's Draft Report: Caring for Older Australians. Available on www.pc.gov.au/inquiries/completed/ aged-care/submissions/subdr0887.pdf (Accessed: May 25, 2016).

Netuveli, G. \& Blane, D. (2008). Quality of life in older ages. British Medical Bulletin 85 (1): 113-126.

Productivity Commission. Caring for older Australians. (2011). Report No 53, Final Inquiry Report, Canberra. Available on http:/ / www.pc.gov.au/ inquiries/completed/aged-care/report (Accessed: January 11, 2016).

Pfefferbaum, B., Richard, L. \& Pfefferbaum, R. L. (2017). A conceptual framework to enhance community resilience using social capital. Clinical Social Work Journal 45(2), 102-110. doi: 10.1007/ s10615-015-0556-z

Reynolds, J. (2015). Stories of creative writing. Working with Older People 19(1): 3-11. doi: 10.1108/WWOP-11-2014-0035

Rural Health Standing Committee (RHSC). (2011). National Strategic Framework for Rural and Remote Health. Canberra: Commonwealth of Australia, ACT.

Rogers, M., Winterton, R., Warburton, J. \& O'Keefe, S. (2015). Water management and healthy ageing in rural Australia: Economic, social and cultural considerations. Environment and Behaviour 47(5): 551-569. 
International Journal of Ageing and Later Life

Rozanova, J., Dosman, D. \& Gierveld, J, (2008). Participation in rural contexts: Community matters. In N. Keating (ed.), Rural Ageing: A Good Place to Grow Old? (pp. 75-86). Bristol, UK: Policy Press.

Ryff, C. (2014). Psychological well-being revisited: Advances in the science and practice of eudaimonia. Psychotherapy and Psychometrics 83(1): 10-28. doi: 10.1159/000353263

Scharf, T. \& Bartlam, B. (2008). Ageing and social exclusion in rural communities. In N. Keating (ed.), Rural Ageing: A Good Place to Grow Old? (pp. 97-108). Bristol, UK: Policy Press.

Skinner, M. \& Hanlon, P. (eds.). (2016a). Ageing Resource Communities: New Frontiers of Rural Population Change, Community Development and Voluntarism. London: Routledge.

Skinner, M. \& Hanlon, P. (2016b). Introduction to ageing resource communities. In M. Skinner \& P. Hanlon (eds.), Ageing Resource Communities: New Frontiers of Rural Population Change, Community Development and Voluntarism (pp. 1-8). London: Routledge.

Skinner, M. \& Joseph, A. (2011). Placing voluntarism within evolving spaces of care in ageing rural communities. GeoJournal 76 (2): 151-162. doi: $10.1007 /$ s10708-009-9283-8

Skinner, M., Joseph, A., Hanlon, N., Haleth, G. \& Ryser, L. (2014). Growing old in resource communities: Exploring the links between voluntarism, aging, and community development. The Canadian Geographer 58(4): 418-428. doi: 10.1111/cag.12087

Stephens, C., Breheny, M. \& Mansvelt, J. (2015). Healthy ageing from the perspective of older people: A capability approach to resilience. Psychology \& Health 30(6): 715-731. doi: 10.1080/08870446.2014.904862

Stones, D. \& Gullifer, J. (2016). 'At home it's just so much easier to be yourself': Older adults' perceptions of ageing in place. Ageing and Society 36(3): 449-481. doi: 10.1017/S0144686X14001214

Taylor, A. \& Payer, H. (2017). Population Ageing in Northern Australia: Seniors' Voices on Ageing in Place. Journal of Population Ageing 10(2): 181-196. doi: 10.1007/s12062-016-9156-0

Tuohy, R. \& Stephens, C. (2016). Older adults' meanings of preparedness: A New Zealand perspective. Ageing and Society 36(3): 613-630. doi: 10.1017/S0144686X14001408 
van Abbema, R., Bielderman, A., De Greef, M., Hobbelen, H., Krijnen, W. \& van de Schans, C. (2015). Building from a conceptual model of the resilience process during ageing, towards the Groningen Aging Resilience Inventory. Journal of Advanced Nursing 71(9): 2208-2219. doi: 10.1111/jan.12685

Vaneeckhaute, L.E., Vanwing, T., Jacquet, W., Abelshausen, B. \& Meurs, M. (2017). Community resilience: Toward a comprehensive conception of community-level resilience. Community Development 48(5): 735-751. doi: 10.1080/15575330.2017.1369443

Welsh, M. (2014). Resilience and responsibility: Governing uncertainty in a complex world. The Geographical Journal 180(1): 15-26. doi: 10.1111/ geoj.12012

Wiersma, E. (2016). Voluntarism, community culture, and ageing in place in resource-based communities. In M. Skinner \& P. Hanlon (eds.), Ageing Resource Communities: New Frontiers of Rural Population Change, Community Development and Voluntarism (pp. 179-192). London: Routledge.

Winterton, R. \& Warburton, J. (2014). Healthy ageing in Australia's rural places: The contribution of older volunteers. Voluntary Sector Review 5(2): 181-201.

Winterton, R. \& Warburton, J. (2016). Civic and voluntary contributions of retirement migrants and their impact on rural community sustainability: Perceptions of local governments. In M. Skinner \& P. Hanlon (eds.), Ageing Resource Communities: New Frontiers of Rural Population Change, Community Development and Voluntarism (pp. 164-178). London: Routledge.

Zeng, B., Brokensha, H. \& Taylor, A. (2014). A report on the policy and economic impacts from rapid growth in the number of senior Territorians. Research Report, Northern Institute, Charles Darwin University. Available on www.cdu.edu.au/northern-institute/research (Accessed: November 1, 2015). 
